\title{
From the Editors: Advancing interdisciplinary research in the field of international business: Prospects, issues and challenges
}

\author{
Joseph L C Cheng ${ }^{1}$, \\ Witold J Henisz ${ }^{2}$, \\ Kendall Roth ${ }^{\top}$ and \\ Anand Swaminathan ${ }^{2}$ \\ ${ }^{1}$ Consulting Editors \\ ${ }^{2}$ Area Editors
}

\section{Correspondence:}

K Roth, University of South Carolina, The Darla Moore School of Business, 1705 College Street, Columbia, SC 29208, USA.

Tel: + 1803777 3604;

Fax: +18037773609

E-mail: kroth@moore.sc.edu

Journal of International Business Studies (2009) 40, 1070-1074.

doi: $10.1057 /$ jibs.2009.4 |
Two decades ago, JIBS published John Dunning's presidential address at the AIB Annual Meeting in San Diego in which he made a passionate plea for a more interdisciplinary approach to international business (IB) studies. Based on a careful analysis of the major economic, social, political and institutional changes taking place at the time, Dunning (1989: 411) observed:

\footnotetext{
[I]n an ever increasingly complex world of international business ... success is founded on some amalgam of [various factors and capabilities], and it is the way in which these discrete - though increasingly interdependent - advantages are combined with each other and with complementary assets in different countries and cultures [that provides] the key competitive advantages of international firms.
}

Building on this insight, Dunning articulated a vision for the IB field that has its "niche" in generating interdisciplinary knowledge by drawing from different disciplines. Toward this end, he urged IB scholars to "read and study well outside our own area of training" (430) and to collaborate on joint research with colleagues in other disciplines. He also recommended that we build an "interdisciplinary infrastructure," offering post-doctoral tutelage for junior faculty entering the IB field. In an attempt to renew Dunning's plea of 20 years ago, this editorial essay seeks to advance greater interdisciplinary grounding in IB research by addressing the following questions:

- What is interdisciplinary research? How is it different from multidisciplinary inquiry?

- Why do scientists conduct interdisciplinary research? What is its main contribution?

- Given the potential of interdisciplinary research in IB, why do we not see more of it? What broad guidelines can be offered to surmount these challenges?

\section{WHAT IS INTERDISCIPLINARY RESEARCH?}

The report Facilitating Interdisciplinary Research from the National Academies Committee on Science, Engineering and Public Policy suggests that interdisciplinary research is:

a mode of research by teams or individuals that integrates information, data, techniques, tools, perspectives, concepts, and/or theories from two or more disciplines or bodies of knowledge to advance fundamental understanding or to 
solve problems whose solutions are beyond the scope of a single discipline or area of research practice (2005: 26).

Aboelela et al. (2006: 341) provide a comprehensive review of the definitions of interdisciplinary research in the literature and, based on their assessment, suggest that it is:

\begin{abstract}
any study or group of studies undertaken by scholars from two or more distinct scientific disciplines. Such research is based upon a conceptual model that links or integrates theoretical frameworks from those disciplines, uses study design and methodology that is not limited to any one field, and requires the use of perspectives and skills of the involved disciplines throughout multiple phases of the research process.
\end{abstract}

A close reading of these two definitions, as well as others available in the literature (see e.g., Porter, Rosessner, Cohen, \& Perreault, 2006; Rosenfield, 1992; Stokols et al., 2003) suggests that interdisciplinary research has three key defining characteristics:

1. The research draws on ideas and/or methods from two or more disciplines.

2. As part of the investigative process, these ideas and/or methods are integrated or mixed in ways so that together they produce something new and useful (in either solving a problem or advancing fundamental understanding).

3 . The resulting product and its value-added contribution could not have been obtained by relying on ideas and/or methods from any one single discipline alone.

Thus, interdisciplinary research places a distinctive emphasis on the integration or combination of ideas and/or methods from different disciplines (e.g., economics, political science, sociology, demography, psychology, law, philosophy, engineering, medicine) and fields (e.g., finance, accounting, marketing, management or strategy, organizational behavior, human resources, entrepreneurship, ethics, health care management, insurance, real estate, public policy, operations). This integration requires the union of different assumptions, causal mechanisms and levels of analysis to form a new internally consistent whole, similar to a painter mixing one or more of the basic colors (red, blue and yellow) to make a new color. We contend this "mixing" is the key element distinguishing interdisciplinary research from multidisciplinary approaches, where scholars from different disciplines essentially work "independently or sequentially" on a common problem based on their own perspectives (Stokols et al., 2003: S24).

Note that the aforementioned definitions do not specify that interdisciplinary research necessarily involves a team of investigators. In fact, some of the most important interdisciplinary studies were conducted by a single investigator, for example, Simon's (1945) seminal work on bounded rationality which combines insights from cognitive psychology and economics, and North's (1990) socio-political-economic analysis of institutions and national development. Thus, one should not equate interdisciplinary research with team-based investigation, although the latter does have a greater potential for input from different areas of specialization.

\section{WHY PURSUE INTERDISCIPLINARY RESEARCH?}

The main reason why scientists engage in interdisciplinary research is the inherent complexity of the phenomenon being studied. Goodman and Blake, for example, observe that in the post-humangenome world, the domain of bio-medical research has changed such that the important questions can only be answered by research teams consisting of scientists that bring together understanding spanning multiple disciplinary backgrounds, including the biological, physical, engineering and computer sciences (2006: 1189). Similarly, in the field of social psychology, Fiske (2006: 293) argues that social relationships:

are not products of individual brains alone; sociality is shaped by the interaction of evolutionary, developmental, neuroanatomical and neurophysiological, psychological, societal, and cultural processes. Because these processes are highly interdependent, we cannot understand any of them in isolation from the others. Thus, to fully understand social relations, we need to link social psychology to ethnography, ethnology, cognitive science, neuroscience, clinical psychology, evolutionary psychology, developmental psychology, economics and management science, and social theory.

These examples clearly illustrate that interdisciplinary research, where the aim is to generate more comprehensive understanding about complex phenomena, is fundamental to advancing the scientific status of an academic field and furthering its paradigm development (Hempel, 1965; Kuhn, 1962).

In thinking about interdisciplinary approaches applied specifically to the field of IB, we contend that many of the important questions we should be addressing in IB similarly concern complex phenomena that can only be explained using multiple 
forms of knowledge and methods. The important IB phenomena that require further theoretical explication are typically multi-level and deeply embedded contextually. Deeply embedded phenomena can be explained only by also understanding related contextual processes. In fact, the phenomena may actually be mutually constituted by these processes or other phenomena. For example, consider questions about the multinational enterprise (MNE) such as the following:

- How can the MNE exploit the diversity of its workforce, customers, suppliers and competitive environments and maintain cohesion, focus and efficiency?

- What is the appropriate balance between contextual knowledge that is country specific, technology specific or function specific; cosmopolitan, integrative or generalist; and on what factors does the balance depend? How can teams, units, subsidiaries, alliances and other organizations best deal with inevitable imbalances in knowledge or perspective?

- How can the MNE coordinate the activity of the increasingly complex geographic and technological network of upstream suppliers, peer alliance partners, downstream buyers and other external stakeholders while still maintaining flexibility, tapping into and integrating new knowledge, and fostering technological and organizational innovation?

- How should the MNE effectively compete with rising competitors from emerging markets who are imprinted with very different national institutional configurations, business models, belief systems and stakeholder relations?

- What is the long-term development impact of foreign direct investment and how can the MNE be more productively harnessed as an engine for economic and social development?

- Why do patterns of international resource flows (e.g., investment, trade, labor and knowledge) deviate from those predicted by existing formal models?

- How can the MNE allay suspicion and fear that can lead to the adoption of inimical (or the failure to adopt beneficial) government policies in home and host countries?

- How can the MNE organize to recognize and grapple with the tradeoff between the short-term benefits of exploiting power and the long-term political and social backlash?
These questions necessarily bring profit-maximizing shareholders together with workers organized in teams and units and divisions across national economic, political, social and cultural boundaries. The MNE and the stock of assets or resources that it owns, employs, transforms or influences is again, after a brief hiatus, growing in economic, political and social importance. MNEs and the economic, political, social and cultural environments in which they do business are increasingly dependent upon a munificent policy environment for investment and for development, yet there is a fundamental tension between local diversity that gives rise to economic opportunities and the need for control that gives rise to the MNE. Thus, moving forward is not about reformulating novel dependent or independent variables; it is about addressing a phenomenon that can only be unpacked by combining theories, concepts, data and methods from multiple disciplines to explore the scope or boundary conditions of multiple disciplinary perspectives and the benefits of their integration.

\section{MOVING FORWARD IN PRACTICE WHILE AVOIDING PITFALLS}

Whereas it is the rare disciplinary scholar who reaches outward across boundaries, IB cannot similarly sustain itself as a field of inquiry if we mimic this insularity. As the primary motivation for conducting interdisciplinary scholarship is the escape from externally defined silos of narrow theoretical and empirical legitimacy, the first principle in implementing such an agenda should be to avoid any hint of the replication of such silos. If substantive advances in research originate when scholars from multiple backgrounds with competing assumptions work together to unpack the actual causal mechanisms that define an observable phenomenon, the way forward cannot be the creation of a group of IB scholars who share a common worldview tackling a problem in parallel to and isolation from scholars in different disciplines. In fact, there may be no surer path to decline in impact, status and insight than for a preparadigmatic field such as IB to take on these dysfunctional characteristics of a well-established discipline.

Almost by definition, an IB scholar cannot simultaneously stay abreast of theoretical and empirical developments at the frontier of any one given discipline as easily as his or her more focused discipline-based peers. By starting from a strong disciplinary or other narrow foundation and adding 
rich knowledge on a specific national context(s) and insights from additional disciplinary or field perspectives, it may well be possible to gain fundamentally new insights that are not available through a narrow disciplinary lens. However, the less we reach out to the frontier of each discipline, the more likely is the outcome of such an effort to be a pale shadow of a novel insight. Knowledge that depends upon combination cannot thrive when the ingredients combined are dated or the mechanisms of their construction are poorly understood. Rather than banding together in isolation, IB scholars should reach outward to incorporate arguments and insights from related disciplines, generating knowledge that is more than the sum of its parts.

To avoid the perils of isolation, scholars in the field of IB should not only stay abreast of and seek to integrate theoretical and empirical developments in related disciplines, but they should also increase their local interaction with scholars from those disciplines. Knowledge moves forward both at the intersection of disciplines and within them. Just because many disciplinary-based scholars are reluctant to incorporate relevant insights from outside their disciplinary boundaries does not mean that IB scholars should be reluctant to incorporate insights from within these same boundaries.

Scholars in IB should join the growing number of interdisciplinary research programs, initiatives and seminar groups organized around phenomena which span multiple existing disciplines and fields, or even foster the development of such activities. Universities, foundations, governments and donors are sponsoring myriad efforts to generate insight into energy markets, nanotechnology, governance, sustainability, communicable disease, complexity, human rights, communications and urban renewal. Such efforts can bring together scholars from across departments and colleges, as well as universities, to share ideas, fund new research and move the frontier of knowledge forward together. As these efforts necessarily involve international organizational activity (i.e., the cross-border challenges of coordinating research, development, finance, production governance, etc.), scholars of IB have a legitimate demand for voice and participation.

A normative argument for voice and participation is, of course, far from a guarantee that such an outcome will be obtained. Admittedly, many such "interdisciplinary" efforts are merely a rebranding of disciplinary-based activity with a far narrower cast of characters and stream of output than the grandiose publicity materials would suggest. Even more perniciously, many initially interdisciplinary efforts are captured by a sub-group of initial participants who squeeze out alternate perspectives, favoring replication and a more singular worldview.

Despite the clear potential benefits of interdisciplinary research for expanding the frontier of knowledge, the typical doctoral student's committee, journal's editorial board or set of referees on any one article, or set of external letter writers and internal tenured faculty evaluating a candidate's promotion tend to be highly focused within a given discipline. As a result, the sensible course of action, particularly for junior faculty, is not to stray far from a clear and relatively narrow disciplinary identity. IB scholars, already distinguished from their "functional" colleagues by the international dimension, are understandably hesitant to become even more difficult to define or characterize by spanning multiple functions, disciplines or fields, and nations in their research.

Consequently, IB scholars tend to follow one of two strategies. First, they form a primary affiliation with scholars in one discipline and a secondary affiliation with IB scholars from that discipline. Or, second, they form a primary affiliation with scholars of IB and a secondary affiliation with scholars from one discipline. Few scholars succeed or truly even attempt to engage colleagues from multiple base disciplinary perspectives (e.g., sociology, psychology, political science, etc.) throughout the life cycle of their research project.

As a result of these structural constraints and rational choices, IB research withers on the periphery of academic discourse. We debate why there are no big questions in IB research (e.g., Buckley, 2002; Buckley \& Lessard, 2005). We insecurely lament the insignificant impact of our research on theory development in the disciplines. We ponder why policymakers and practitioners do not seize upon the insights we offer into their latest global threats and challenges. We gossip about the latest university to eliminate its IB group and chuckle at the latest effort to infuse each discipline with an international perspective. We decline further in impact, insight and status.

What if, instead, we joined or formed interdisciplinary research teams to analyze the growth of alternate energy sources and contributed to the frontier of knowledge on industrial policy, the development and diffusion of disruptive 
innovation, lobbying, and influence strategies and contributed to the rise of an alternative to oil? What if by participation in the interdisciplinary study of infectious disease we contributed to the literatures on alliances, bottom-of-the-pyramid innovation, and intellectual property protection and saved lives? What if work on urban renewal generated insight into multi-stakeholder governance, institutional change and sustainable development and fostered tens of billions of dollars in new infrastructure investment?

\section{CONCLUSION}

We offer a call to arms to the field at a moment of threat and potential. Financial constraints upon research and academic institutions are sure to strengthen in the short term and may not recover for some years. Pressures for rationalization, simplification and streamlining will typically be directed by discipline-based scholars and thus more than proportionately target IB research, faculty lines and doctoral programs. Yet, at the same time, overcoming the financial challenges faced by our universities, their donors and their governments so clearly requires knowledge that spans national contexts and disciplinary boundaries that we are well placed to engage in and contribute to the research debates that emerge in this time of crisis and introspection.

Look around your university. Find a group of scholars coming together around an important topic involving IB in which you are personally

\section{REFERENCES}

Aboelela, S. W., Larson, E., Bakken, S., Carrasquillo, O. Formicola, A., Glied, S. A., Haas, J., \& Gebbie, K. M. 2006. Defining interdisciplinary research: Conclusions from a critical review of the literature. Health Services Research, 42(1): 329-346.

Buckley, P. J. 2002. Is the international business research agenda running out of steam? Journal of International Business Studies, 33(2): 365-373.

Buckley, P. J., \& Lessard, D. R. 2005. Regaining the edge for international business research. Journal of International Business Studies, 36(6): 595-599.

Dunning, J. H. 1989. The study of international business: A plea for a more interdisciplinary approach. Journal of International Business Studies, 20(3): 411-436.

Fiske, A. P. 2006. Social relations: Culture, development, natural selection, cognition, the brain, and pathology. In P. A. M. Van Lange (Ed.) Bridging social psychology: Benefits of transdisciplinary approaches: 293-300. Mahwah, NJ: Lawrence Erlbaum Associates.

Goodman, S. R., \& Blake, C. A. 2006. The future of interdisciplinary research and training: How to conquer the silo guardians. Experimental Biology and Medicine, 231: 1189-1191. interested and through which you can expand the frontier of knowledge in IB and in an adjoining discipline or field. Attract doctoral students and post-doctorates to join the effort. Generate insight by listening and contributing to a broad-based process of inquiry. Push back against efforts to narrow the focus to one worldview or discipline. Tell others, including policymakers and practitioners, about the successes and failures of your efforts. Repeat the process.

Commitment to such an open and collaborative effort in which IB scholars join with their school and university colleagues can help design more effective corporate strategy and public policy, something that the founding fathers of IB envisioned when they created The Academy some 50 years ago.

\section{ACKNOWLEDGEMENTS}

Although four names are listed as co-authors of this Letter from the Editors, the opinions expressed here represent the collective view of the JIBS Editors. We benefitted much from extensive single blind discussions with the entire JIBS team (Editors, Consulting Editors Board and Editorial Review Board) as well as with Editor-in-Chief Lorraine Eden, Stephen Kobrin and Mauro Guillen during the preparation of this editorial. Also Heinsz thanks Stanford University for hosting him as The UPS Visiting Professor of Civil and Environmental Engineering during the period this article was written.

Hempel, C. G. 1965. Aspects of scientific explanation. New York: Free Press.

Kuhn, T. S. 1962. The structure of scientific revolutions. Chicago: University of Chicago Press.

National Academies Committee on Science Engineering and Public Policy (COSEPUP) Committee on Facilitating Interdisciplinary Research. 2005. Facilitating interdisciplinary research. Washington, DC: National Academies Press.

North, D. C. 1990. Institutions, institutional change and economic performance. New York: Cambridge University Press.

Porter, A. L., Rosessner, J. D., Cohen, A. S., \& Perreault, M. 2006. Interdisciplinary research: Meanings, metrics and nurture. Research Evaluation, 15(3): 187-195.

Rosenfield, P. L. 1992. The potential of transdisciplinary research for sustaining and extending linkages between the health and social sciences. Social Science and Medicine, 35(11): 1343-1357.

Simon, H. A. 1945. Administrative behavior. New York: Free Press.

Stokols, D., Fuqua, J., Gress, J., Harvey, R., Phillips, K., BaezcondeGarbanati, L., Unger, J., Palmer, P., Clark, M. A., Colby, S. M., Morgan, G., \& Trochim, W. 2003. Evaluating transdisciplinary science. Nicotine \& Tobacco Research, 5: S21-S39. 